\title{
Research and Education in the Contemporary Context of Art History From the Vision to the Art
}

\author{
Weikun Hao \\ Hebei Institute of Fine Art, Shijiazhuang Hebei, 050700, China
}

Keywords: Oil painting Techniques; Digital Image; Teaching

\begin{abstract}
As is known to all, today's art education, its function has been far beyond the scope of training professional art talents. And from the perspective of the status quo of higher art education and skill training compared with history research, history research obviously in a weak position. From the Angle of art, art history is one of the important part of human art and culture, several conclusions show that for the study of art history and also learn the meaning of the obvious, such as improve the level of the fine arts disciplines, from the pure skills subject ascended to the status of the humanities; For today calls a "visual arts" or "visual culture" study, art history research is necessary; In carrying forward traditional culture today, the study of art history and learning will make human have more opportunity to participate in the fine arts with the human, and life, and emotion, contact with politics and history, for more understanding of cultural phenomenon.
\end{abstract}

\section{Introduction}

Plays a role in history of art history, art history research in the history of the grand is indispensable in the background, the history and culture is the concept of two inseparable. Obviously, for art history research to let a person produce both witness the massiness of history, and to experience the many things like the ramifications of fine arts. Today we are on the study of art history, there is still a feeling of confusion and disorder, but the academic circles has been working hard. Such as art history study held annual meeting of the state colleges and universities, is the art historiography circle for in-depth research of art history and expand constantly trying. On November 15, 2014 annual meeting of the eighth national institutions of higher learning fine art historiography, further to the research of art history and experience exchange, through to reflect on the knowledge paradigm in the study of art history and the present knowledge context, for the research of art history and art history education to explore a kind of new possibilities.

\section{Tracing Huge and Subtle From its History Background}

Some people say that the history of art is the history of human show their creativity, is a part of the result of the creation of art history, beautiful and meaningful. Therefore, the study art history like study art history background, complex and far-reaching, complex and subtle. However, whether the research background of hong kuo of art history and subtle to what extent, do not interfere with art history research from the Angle of view to the way of development and change.

Classic ancient Chinese literature in the symbolism of the future generations, called is because in the literature transmission, in the visual culture, the image is how because is a very complicated problem.

An Yuan Li said: "some people say literati painter's art is as writing ink play, rarely contain special meaning, but the fact is not so simple, when the life trajectory of literati painters fell in the specific historical fork, he will naturally "something hard to tell" into ink, as a kind of spiritual self 
settle way. Today, the reason we're able to image from the perspective of the literati paintings depth interpretation, that is due to these works, from the creation of a start, he was artist set a secret image, how to unlock these secrets, the most important way is to need to be familiar with the relationship between works and artists in the creation of context. In addition, Chinese also understand some of the ancient classic cultural motif, especially literary and religious motif. We used to speak, later literati paintings often use pastiche as a new interpretation of creation, but this is only a schema or strokes of reference, behind the concept is idealized ink ecological building. [1] Image significance of literati painting allusions, schema reference only the form, behind the content is loaded with more profound cultural accumulation, even with the connotation of a cultural motif condense in together. This is, of course, from the perspective of image, literature and classical visual experience that significance of image's existence is due to the implantation of the cultural motif; conversely, if we from the literary point of view to study literature experience of Chinese classical painting, such as Gu Kaizhi "Luo Fu map" will know, a literary motif has become the classic rely not only on oral and written by wide to eulogize, in the meaning extension and dissemination process, the image will be one of the important ways. "

As is known to all, today's art education, its function has been far beyond the scope of training professional art talents. And from the perspective of the status quo of higher art education and skill training compared with history research, history research obviously in a weak position. From the Angle of art, art history is one of the important part of human art and culture, several conclusions show that for the study of art history and also learn the meaning of the obvious, such as improve the level of the fine arts disciplines, from the pure skills subject ascended to the status of the humanities; For today calls a "visual arts" or "visual culture" study, art history research is necessary; In carrying forward traditional culture today, the study of art history and learning will make human have more opportunity to participate in the fine arts with the human, and life, and emotion, contact with politics and history, for more understanding of cultural phenomenon.

\section{Look at the History of Art in the Changes of Visual Culture}

The philosopher writer "statements and self analysis, in the whole human history writings such as sea zhonghao. And focus on the visual arts in the presentation of self image, and presented to the cultural and psychological analysis is very little. In the fine arts and the development of contemporary art history background of near Xuan dense with words to judgment and thinking, and to analyze the hidden behind the perception of change and cultural change, is still the topic a promote and reconstruction efforts.

Tianjin Academy of fine arts art history professor Shao Liang by present behind the perceptual characteristics and cultural change analysis of vision from 1919 to 1985, pointed out in fine arts subject of common concern "new method" today, examines the history of art and the art of writing history, not only in thin section and in the overall field of vision and the idea are facing a profound change.

If the focus of our study is a specific case in Chinese contemporary art history, it seems to be too broad for 1985 to 1919. Chose this time, Shao Liang concern is in the transition to the art history behind the image of visual perception and visual experience, and some subjects expand preliminary analysis, in his view, between 1919 to 1985, related to the visual elements and its derivative problems, show the time interval between some inherent continuity and consistency; in 1919, start the update an important concept is the history of Chinese thought, but also a modern life began, for example, this year is the popularity of China's domestic camera to. [2]

"Behind the changes in the artistic style and self concept of continuous extension, in fact is not 
only a kind of artist's personal style and found the spontaneous power, and reflects the complex interaction between the changes of living environment, human visual attention and even subtle habits of personal choice; and in the period from 1919 to 1985, the" self "the writing of Chinese art, is a kind of special deep, creators in the modern cultural environment for the expression of their own language, in different information and experience visual habits of seeking a balance; change process is similar to eastern and western visual art history in the event of a universal effect the change of contemporary visual culture; Chinese based on the study on this period of history of visual experience, with some special advantages and urgency: only A camera as a new visual experience, caused by the relevant cultural reaction, western the perceived relevance of change has occurred in more than 100 years ago, we in the study of literary history reconstruction of more than 100 years ago related to visual perception becomes more diaphragm and difficult; and now, China contemporary visual changes still exist in the us today living visual memory, relevant to the topic of investigation and research, in the idea not lag, on the contrary is more a special freshness and persuasion, to China given gaze speech art world, with a special academic exploration and irreplaceable."

As a result, Shao Liang summed up the visual history of self image, the importance of the visual experience and cultural induction in the study of its style:

First, art history of the self is not a new topic, but this is our further study of the argument is an important point, we today art history as a discipline education practice, we still need to further break the artist the myth of the self - understanding, is the art of "self" in a more rational concept of history and cultural history.

Second, we have a written description of the visual experience, there may be some inherent limitations of the problem. At the very least, a college art history textbook, which is still mainly based on the clue of style, has been gradually deviated from the contemporary academic research in many aspects, even the actual visual perception.

Third, behind the style of visual experience and culture induction, is by no means a broad generalizations, but art history to one of the important point to deepen.

\section{To Study the History of Art From the Perspective of Multi Perspective}

Manuscripts is one of China in the ancient heritage of knowledge, the most important media, and one of the most important discoveries undoubtedly accidentally discovered more than a century ago Dun huang suicide note, a large number of manuscripts to bring the world "Dun huang" doctrine, they are 4 to 11 century medieval society of valuable first-hand data.

Beijing Institute of clothing art history department Associate Professor Zhong Ming Qiu, Dunhuang outside, there are still sporadic or smaller manuscripts found. These manuscripts should be of considerable importance. By Zhong Ming Qiu attention a is now in the possession of the Zhejiang Provincial Museum, the Buddha Amitabha Sutra illustrations of this sutra pieces (because of the land for Wenzhou Longquan a pagoda, clumsy paper referred to as for "Longquan"), makes a textual research on the dating and the reflection on the study of art history in the extant manuscripts of the era of the authenticity and issues should be held the attitude and research method and angle.

Earlier scholars concluded that the age of the Tang and the Five Dynasties, even the song, Qiu Zhongming think this is debatable dating. In recent years, she visited the Wenzhou Museum, Zhejiang Museum and other places, have the opportunity to examine the Sutra pieces. On the part of the painting: this draw the content contained in a building -- mutual clusters of 3 treasure Pavilion, Qibao pool, pedestal and all kinds of wonderful flowers, figures and costumes, the painting pen colors, according to the content of the painting, painting language, write classics wind as well as the 
Buddhist version, suggestions will be the era for the Tang. Will the treasure Pavilion and the Mogao Grottoes of Dunhuang No. 321 cave, cave 445, cave 148, 156 Grottoes paintings of the pavilion and Wutaishan Nanchan temple hall of comparison, "Qibao pool, lotus seat, and datura flower with the Dunhuang frescoes, the Tang Five Dynasties moment by comparison, fine trial this volume treasure Pavilion of the use of color, also conforms to the system of the Tang Dynasty. Liang Sicheng according to the Dunhuang murals of summed up the main color of the Tang Dynasty Buddhist temple, which is red, white and ochre: timber is red, stucco or brick walls white, contrasting; roof grey, the "tiles" color, no glass ornament and brightly. [3] In Longquan the drapery is relatively thick, since the pen pen quite close to the change, the style is the style of tang. In the soil with the sentient beings of pant and Dunhuang in the middle and late Tang Dynasty characters with similar pleats.

Based on the above investigation, Zhong Ming Qiu said: "worthies is mainly based on morphological or the history of a certain angle to carry on the inspection, if we can starting from the multi angle, multi discipline and learning in classical literature, history, archeology, history of calligraphy, painting history and the history of science, and other disciplines cooperation, it seems we can expect a more reliable chronology. Of course, this requires the cooperation of scholars from various disciplines, is a very large project. If you can build an interdisciplinary study of the academic community, it must be a blessing in academic circles."

Although the core of art China lies in the history of literature and art theory research. And in the view of Yu Yang, associate professor of Central Academy of fine arts, cross-border research and Study on the essence of is always exists in various disciplines two methods, both the advantages and disadvantages of non each reference can not explore the physical and investigate its way. Stressed on the rule of interpretation of traditional art research methods have shown two different directions: one is the artists and works placed in the social environment, from social history and anthropology perspective, to explore the art of historical significance and social functions, this approach often works of art as the data and evidence from image themes and content in obtaining historical value; the second is from the art ontology research perspective, focusing on the artistic creation, appreciation and the history of literature of phylogenetic relatedness, summarizes the artistic creation of media materials and techniques of the law, especially in ancient Chinese painting exhibition, the painting works of traditional art's ontology and practical experience.

For the study of painting art research Chinese China, return to the "body", Yu Yang think mainly in three aspects: one is to China painting theory literature review research system, through the classical text for the traditional China painting history literature review and re cognition, to regain the combination of painting creation and theory closely the ancient painting history, painting in the traditional value system, basic principle and interpretation of the text, Chinese painting painting, painting; second is associated with recovery Chinese painting research and literature, poetry, and study through the works of the charm and artistic conception and style of traditional theory, grasp the core value system of China art as the main line, the traditional literati painting freehand and poetic as the main artistic characteristics; third is to open up the painting origin and development with the macro background Association, and strive to restore the investigation and cognition of many phenomena in the history of Chinese art, also fully understand art characteristics of the times, will now contemporary art exhibition and cultural and art criticism also really into the category of Chinese art history research, implementation for the phenomenon of contemporary art academic collation, avoid history, theory, assessment bias separated from each other. 


\section{To Express the Charm of Art History China From outside the Box Cross Cultural Studies}

Comrade Deng Xiaoping once said: "we want to learn advanced science, technology, operation and management methods and any other useful knowledge and culture to the developed capitalist countries, closed, rest on its laurels is stupid. However, it belongs to the cultural field of things, we must use the Marx doctrine of their thinking and performance methods of analysis, identification and criticism." In the view of western scholars for the study of Chinese art history, we should also hold the same attitude.

Since the late nineteenth Century, the western art history scholars began to study and write the history of Chinese art. "On the one hand, the western art history has gradually extended from the Western European center to the East, India, China and Japan. After entering the twentieth Century, the attention of Chinese art has become the inevitable trend of the development of the western art history. On the other hand is after the Opium War, Westerners continue to enter the Chinese mainland, examine the remains of Chinese art, Chinese art collection, during which before a large number of Chinese porcelain (including the Opium War into European porcelain and crafts), bronze ware, ceramics, calligraphy, painting, sculpture works inflow European and American museums, or in a private collection and make Westerners to Chinese art is intuitive, but also facilitates the European art history scholars study of Chinese art history, French Liao Ba Luo, British Bossier and American Ferguson and other western scholars, writing the the first a group of Chinese art history books. " Academy of Fine Arts, Tsinghua University professor Chen Chiyu for western scholars concerned about the history of Chinese art has a clear understanding of the historical reasons.

And the attention of Chinese art in the 20th century and the conscious works of Chinese modern artists, said British famous art historian Sullivan (Michael Sullivan 1916 - 2013) played a pioneering role. Su Liwen is the first western attention China modern art, modern art and the China art historians to Western system. The 20th century Chinese art and artists "is not only Westerners to understand Chinese modern art of window, won the praise of the Western readers, the book also for us to study the history of Chinese art in the 20th century provides a new perspective and method, worthy of our careful reading and drawing.

Chen Chiyu introduction, "Twentieth Century Chinese art and the artist" is Su Liwen's 60 years of long-term thinking and research of crystallization, paid a lot of efforts of the author. Book divided into two volumes, a total of 62 words, attached color and black and white pictures hundreds of pieces, and attached to the 1800 Chinese contemporary artist biographies. The book to the Western perspective, the general picture of the twentieth Century Chinese art panorama, is a system of unique views of the twentieth Century Chinese art history. [4]The book chronologically divided into five parts, respectively, from 1900 to 1937: the impact of the West; from 1937 to 1949: the war of resistance against Japan and the war of liberation; from 1949 to 1976: the art of Mao Zedong era; the art of other species and regions; Mao: art into new period. The book from the beginning of the twentieth Century Beijing traditional painting and painting of Shanghai speaking, Beijing Jincheng, Chen Shizeng, Qi Baishi and Wu Changshuo of Shanghai, Pan Tianshou, Huang Binhong and other artists and works to analyze and reveal their great influence on twentieth Century Chinese painting, and the Beijing art Chen Duxiu's revolutionary thoughts, explore new Chinese painting and Western compromise concept art revolution Shanghai Liu Haisu and Guangdong School of South of the Five Ridges on behalf of Gao Jianfu et al., shows the author has a keen insight to artists and works, and the related new ideas, the concept of art art for artistic creation, have accurate grasp, this has become a feature of the book, the analysis will be the social ideological trend and artistic concepts and ideas, with the analysis of artistic creation and artists combine to reveal art phenomenon back 
The root of social thought. This characteristic is also reflected in he at the beginning of the 1930s Shanghai to Ni Yide, Pang Xunqin as a representative of billows society analysis on that juelanshe by western expressionism, abstract expressionism, cubism, super realism and dada concept and form. The book on the new woodcut movement and comics, during the period of Yanan revolutionary art, after the founding of new China workers and peasants art activities, art of the "Cultural Revolution", and in the 1980s fashion art, the regeneration of traditional Chinese painting, in the late 1980s and the early 1990s cutting-edge or avant-garde artists, and sculpture, modern prints, special chapter carries on the elaboration. Especially the author takes into account the full display of the achievements of the 20th century Chinese art, in addition to the focus on the introduction of the mainland artists, and also listed a special section introduced China's Taiwan and Hong Kong art, and moved to the achievements of the Europe, America and Southeast Asian Chinese artists. Such as the China Taiwanese artist Lee Shih Chiao, Yang Yingfeng, Ju Ming, from the mainland to Taiwan Huang Junbi, and represented by Liu Guosong Taiwan modern painting "may painting society and settled Ding Yanyong of Hong Kong and Hong Kong artist, Wen building, Lu Shoukun, introduced, living in Europe and the United States painter pan Yuliang, Chang Yu, Zao wou $\mathrm{Ki}$ and $\mathrm{Chu}$, had Youhe artistic achievement for the analysis of. This allows readers to read the book, the Chinese art and artists, both the mainland and Hong Kong and Taiwan, or moved overseas Chinese artists, have a comprehensive understanding and grasp.

Obviously, the research results and methods of overseas scholars have great significance to the promotion of the Chinese art research since the 80's of last century. Yu Yang through the study of overseas Chinese art reflection, analysis of the overseas Chinese art research and limitations of the enlightenment, that is, the positive and negative effects of overseas Chinese art research methodology.

For the study of painting art research Chinese China, return to the "body", Yu Yang think mainly in three aspects: one is to China painting theory literature review research system, through the classical text for the traditional China painting history literature review and re cognition, to regain the combination of painting creation and theory closely the ancient painting history, painting in the traditional value system, basic principle and interpretation of the text, Chinese painting painting, painting; second is associated with recovery Chinese painting research and literature, poetry, and study through the works of the charm and artistic conception and style of traditional theory, grasp the core value system of China art as the main line, the traditional literati painting freehand and poetic as the main artistic characteristics; third is to open up the painting origin and development with the macro background Association, and strive to restore the investigation and cognition of many phenomena in the history of Chinese art, also fully understand art characteristics of the times, will now contemporary art exhibition and cultural and art criticism also really into the category of Chinese art history research, implementation for the phenomenon of contemporary art academic collation, avoid history, theory, assessment bias separated from each other.

"Since the end of 70" s last century, European and American academic research methods and the introduction of the concept of art history has greatly expanded the perspective of China's local art research. Especially the western scholars for research of Chinese art, the local art scholars see the academic ideas and methods from the theory angle to expand the possibility of Chinese art history research. Sullivan, James Cahill, Jerome silbergeld, ban Zonghua, Luo Yue, such as Europe and the United States scholar of Chinese art history writings were translated and introduced to China mainland art historians, Fang Wen, Chu Tsing Li, shin, Chou Ju Shi, Wu Hung, Shou Chien Shih, Wang Yuejin, white modest and prudent, overseas Chinese art history scholars worked in an American university or art museum, to study the problem of western academic methods of 
traditional Chinese art, these interlingual, cross culture research in mainland scholars attracted unprecedented attention and response. "

Translated and introduced the method and concept of overseas study of Chinese fine arts, have a profound impact on the study of Chinese art history since the new period. Yu Yang believes that on the one hand, the Chinese scholars in reviewing China's own painting tradition of historiography. On the other hand more fit into the needs of the modern discipline system as the subject of higher education of art history, and institutions of higher learning the art history scholars group is clearly part of the study of Chinese art, the most important force, with the value of Enlightenment of overseas research methods on fashion and in the inheritance of teachers as well as students get the uplift. If it is said that when translating works for Chinese art research scholars had their eyes opened, then in 20 years later today, when the research results of the western art historian has been relatively systematically introduced and profound influence of Chinese art circles, its construction meaning and bureau of limited, should be further consolidation and split into two dialectical thinking. First, methodology of interdisciplinary reference to western academic in the field of art studies as a branch of pure humanities, sociology, anthropology, image, style, form analysis, psychology and other modern western scholars study the phenomenon of art history are often used method, its advantage is art history research can be shared cultural history, history of thought and philosophy theories and research models, but at the same time professional and body art, together with the cultural characteristics of Chinese art, often by the grand "integrity" and pervasive "deconstruction. Especially when the research objects point to the Chinese traditional art, this kind of "cool rationality" may bring the dislocation is particularly prominent. Or in accordance with the concept of western academic system and logic will construction of Chinese art history research is the idea of "humanities", itself should get enough of the argument and reflection. Secondly, for foreign research perspective and methods without discrimination introduced to apply, often ontology research direction is introduced to spur even discrimination size. Even if it is in the same sense, it may come to different or even opposite conclusions in the face of the same research object. In fact, because of the values, the methodological differences, for many years both at home and abroad of China art research exists the phenomenon with abound.

From a more macro perspective view of scholarship is also facing exposure to certain cultures and social field "ecological environment". [5]A specific cultural system will restrict and determine the methodology and values of a subject, and also construct the ontology of this subject. When a subject or field of "international" has been flocking to the attention, should in turn to construct their own cultural system and fit the value standard of the national culture characteristics. On this issue in the ocean that treat a subject area or a culture of openness, and in the face of an established tradition should be rational and conscious attitude is the same truth, only to be able to play in go, but also to "out", in different periods have not the same period tasks and proposition, hair and extension of the strategy choice, also need courage to sober wise judgment and upstream.

Taking history as a mirror of the times as a reflection of the scale of art education from the 90 's, the Chinese mainland scholars for the history of Chinese art and its own academic tradition of thinking and the return has begun. For the case of painters and painting in Chinese art history discussion, re focus on specific paintings, historical details and painting literature study of Chinese fine arts. Yu Yang said: "the steadfast rigorous traditional research atmosphere, objectively reversed the simply to Western ideas for Chinese art of theoretical interpretation of vague, also timely prompt the body of art history research. Especially in the western Chinese art research scholars are accustomed to the social environment and artistic combination of, pay attention to the historical, political, economic and other external factors for the painter's painting style of academic trend, 
some domestic scholars will study re transferred to point to introversive perspective of Chinese art ontology, to implement for clarifying the case facts and finishing, for the study of Chinese art to the effective role in the construction of. In this point of view, the discovery of ancient and modern art history literature, sorting has top priority is the study of Chinese art, for obvious reasons: for as the visual arts in the arts disciplines, for the ancient art history works of visual experience and cognitive theory, this is art research academic the deep origin. To sum up, today's study of Chinese fine arts can not meet to just explore 'peripheral' problem 'detour said Zen', or is caused by the methodology and research ideas of superficial cross-border external 'prosperity', and it should be possible to return to the ontology of art creation, for visual images and art ontology language for practical inquiry. Only in this way, the Chinese art research can complete the self construction in the self adaptation, self sufficient academic foundation and the ideological context, so as to establish its own identity and personality."

If it is said that when translating works for Chinese art research scholars had their eyes opened, then in 20 years later today, when the research results of the western art historian has been relatively systematically introduced and profound influence of Chinese art circles, its construction meaning and bureau of limited, should be further consolidation and split into two dialectical thinking. First, methodology of interdisciplinary reference to western academic in the field of art studies as a branch of pure humanities, sociology, anthropology, image, style, form analysis, psychology and other modern western scholars study the phenomenon of art history are often used method, its advantage is art history research can be shared cultural history, history of thought and philosophy theories and research models, but at the same time professional and body art, together with the cultural characteristics of Chinese art, often by the grand "integrity" and pervasive "deconstruction. Especially when the research objects point to the Chinese traditional art, this kind of "cool rationality" may bring the dislocation is particularly prominent. Or in accordance with the concept of western academic system and logic will construction of Chinese art history research is the idea of "humanities", itself should get enough of the argument and reflection. Secondly, for foreign research perspective and methods without discrimination introduced to apply, often ontology research direction is introduced to spur even discrimination size. Even if it is in the same sense, it may come to different or even opposite conclusions in the face of the same research object. In fact, because of the values, the methodological differences, for many years both at home and abroad of China art research exists the phenomenon with abound.

It is undeniable that the media determines the content, the way to determine the direction and will lead to different conclusions. Affected by the western art history research methods and the logic of academic, after the initial stage of scientific and systematic transformation, the study of Chinese art need more body return to its own academic tradition and the establishment of new academic points. Reporters that, for the higher art education, experienced a wave of western culture shock, rational return of China's art research will undoubtedly have oriented effect on art education, this return to thinking of ontology of art, whether in art education from the macro context of times? Higher art education should pay more attention to the inheritance and innovation of the ontology and technical methods of art research, or to pay more attention to the role of social and era development from the cultural context of the times. These are all important issues in front of art research and art educators.

It can be said that there are still many problems in the setting of art history curriculum and the distribution of teachers in higher art education. As enough attention in the art history course has not been up to the leadership down to the students, there are a lot of school, especially the non professional art college art education is still mainly to teach art skills, for the history of the fine arts 
curriculum with little or no, even if there is, the learning space is only limited to the classroom, classroom and textbook completely replace the museum and all kinds of historical relics, learning content is confined to classics. This for the fine arts discipline construction can not is a serious gap.

Stanford University Professor Eisner advocated DBAE teaching mode is to discipline based art education, art learning should include four aspects: art creation, art history and art criticism and aesthetics, and emphasizes the unique value of art education and can not be replaced. It can be seen that the history of the art of research and learning is an integral part of the education of art, and should be combined with the other three. Of course, the general discussion of art history course is biased, but at least to the domestic art history research and art education plays a role in the enlightenment.

Although the significance of the study of art history and education has obvious, but most of the time still remain in the form of written, like a lot of art history master and doctoral graduate students to apply for a job, often be asked have the skills and techniques class. In the opinion of some schools, only the history course is equivalent to raising the white one. Of course, this phenomenon is being changed, but the history of fine arts teaching is to be implemented from two aspects of quantity and quality, is still a problem. Anyway, the role of the education of history of art in the art environment and cultural environment of what is reflected in where, is a huge topic, it is difficult to pass limited words to express, but learning the art history for the learner's own thinking system establishment of help, and make the creators understand art created by the creator the restriction of time and environmental factors, for in the history of art works and the author's understanding, we can inherit and innovation by, in creative thinking of a diffuse without a clue found to follow the clues.

Strictly speaking, not overnight effect of education of art history to show, and the concept of art education changing constantly reminded that art education workers, for research and study of the history of the fine arts, can let people have the opportunity and carrier of the more reflective, those in the past, for traditional art events and historical facts in the cultural view of vision to carry on the inspection, may be able to provide a new development ideas for today's art education, but also for the inheritance of traditional culture and carry forward to provide a new perspective.

\section{References}

[1]Zhu Shaohou. China ancient history, Fujian people's publishing house, 1991 Edition

[2] Qingchao- ke. Education reform and innovation of technology push [J]; China audio-visual education. 04-2012

[3] Guo-wei liang. Imaging techniques: a human life of the overall characterization [J]. Journal of dialectics of nature research. 2005-08

[4]. SuWei. Introduction to digital imaging technology in the application of the oil painting creation and images $[\mathrm{J}]$. The shenzhou. The 2013-05

[5]. Liu Shuang. Introduction to modern integrated imaging techniques in representational easel painting to explore the application [D]. Shanghai normal university. 2010-5 